\title{
Physical Phenomena in Nuclear Thermal Hydraulics and Current Status
}

\author{
F. D’Auria ${ }^{1 *}$, N. Aksan ${ }^{2}$, H. Glaeser ${ }^{3}$ \\ ${ }^{1}$ University of Pisa, DESTEC-GRNSPG, L.go L. Lazzarino 2, 56100 Pisa - Italy \\ ${ }^{2}$ Scientific Consultant, Haldenstrasse 35, CH-5415 Nussbaumen, Switzerland (Retired from Paul Scherrer Institute, Villingen - \\ Switzerland) \\ ${ }^{3}$ Consultant, Herbstrasse 9, 85386 Eching, Germany (Retired from Gesellschaft fürAnlagen- und Reaktorsicherheit, Garching - \\ Germany)
}

Corresponding Author Email: f.dauria@ing.unipi.it

https://doi.org/10.18280/ti-ijes.650101

Received: 10 November 2020

Accepted: 9 February 2021

\section{Keywords:}

phenomena in nuclear thermal-hydraulics, experiments, scaling, numerical codes, nuclear reactor safety

\begin{abstract}
116 nuclear Thermal-Hydraulic Phenomena T-HP are identified in the present paper, following documents issued during the last three decades by the Committee on the Safety of Nuclear Installations of Nuclear Energy Agency of the Organization for Economic Cooperation and Development (OECD/NEA/CSNI) and by the International Atomic Energy Agency (IAEA). The derived T-HP list includes consideration of experiments performed in Separate Effect Test (SET) and Integral Effect Test (IET) facilities relevant to reactor coolant system and containment of Water Cooled Nuclear Reactors (WCNR). We consider a dozen WCNR types: Pressurized Water Reactors (PWR), Boiling Water Reactors (BWR), Russian reactors (VVER-440, VVER-1000 and RBMK), pressure tube heavy water reactors by Canada (CANDU) and India (PHWR) and so-called 'advanced' reactors (e.g. AP-1000 and APR-1400 designed in US and Korea, respectively).

We envisage a variety of applications for the T-HP list. Four of the phenomena are helpful to characterize the current state of art in nuclear thermal-hydraulics: Counter Current Flow Limitation (CCFL), Critical Heat Flux (CHF), reflood and Two-Phase Critical Flow (TPCF). Furthermore, the T-HP identification contributes to addressing the scaling issue, performing uncertainty evaluations, developing constitutive equations and 'special models' in codes and prioritizing the research.
\end{abstract}

\section{INTRODUCTION}

When characterizing indispensable nuclear technology areas or disciplines that need specific development to make possible the exploitation of fission energy, one may converge on the following shortlist (not in the order of importance):

- Nuclear Thermal Hydraulics (NTH),

- Radioprotection,

- Neutron Physics,

- Structural Mechanics.

NTH is on the focus in the present paper. Thermal Hydraulic Phenomena (T-HP) and computer codes are key elements of NTH. The former constitutes the basis of the empirical evidence; the latter is the repository of modeling expertise and competence. The overall NTH implies a universe of knowledge as discussed in [1].

The scope here narrows down to transient NTH and to fundamentals, i.e. the T-HP, important for applications to the safety of Water-Cooled Nuclear Reactors (WCNR).

Any transient part of the Design Basis Accident (DBA) envelope in WCNR is at the origin of an accident scenario (AS). Phenomenological Windows (Ph.W) allow subdividing the time evolution of any AS; then, T-HP characterize Ph.W. Physical Parameters, with proper Ranges (PP\&R), are part of modeling and constitute the solution of numerical code calculations. Therefore, one may depict the logical frame:

\section{$(\mathrm{WCNR}+\mathrm{DBA}) \rightarrow \mathrm{AS} \rightarrow \mathrm{Ph} . \mathrm{W} \rightarrow \mathrm{T}-\mathrm{HP} \rightarrow \mathrm{PP} \& \mathrm{R} \in($ code- calculations-results) $\leftarrow$ modeling}

Properly scaled Separate Effect Tests (SET) and Integral Effect Tests (IET) constitute the experimental database. Whereas integral test facilities, at the origin of IET, are usually designed to follow the performance of a reference reactor system in various off-normal conditions or accident transients, SET focus on the behavior of a single component, or on the features of one or a limited number of T-HP.

Already in the year 1987, the OECD/NEA Committee on the Safety of Nuclear Installations (CSNI) published a document that systematically identifies a set of T-HP and tests detected from IET. Those experiments and phenomena provide the best basis for the assessment of thermal hydraulic codes, [2]. A couple dozen reports, in forthcoming two decades, constitute the bases for the identification and the characterization of $116 \mathrm{~T}-\mathrm{HP}$, [3]. The description of individual phenomena and the connection between T-HP and AS are the topic of Chapters 6 and 15 of [1].

A two-tier objective for the present paper is the use of T-HP for moving the frontiers of NTH. The two tiers are: (a) to propose multiple roadmaps for exploiting the knowledge associated with phenomena, see also [4], and (b) to provide a view of current modeling capabilities. We achieve the latter objective by considering four T-HP: Counter Current Flow 
Limitation (CCFL), Critical Heat Flux (CHF), reflood and TwoPhase Critical Flow (TPCF).

Background information about NTH phenomena, the list of 116 T-HP, envisaged applications of phenomena and selected modeling limitations constitute the content of the paper.

\section{BACKGROUND INFORMATION FOR T-HP}

In 1943, soon after the proof of the reactor chain control and sustainability, e.g. [5], the endeavor started for the design of WCNR. Thermal hydraulics $(\mathrm{TH})$ had a key role since the beginning, Figure 1 (e.g. Chapt. 2 of [1]). A number of design situations required specific research and the need to consider NTH appeared at the early stage of this period.

Two main breakthrough events provided impulse and directions to the development of NTH: 1) the introduction by US Atomic Energy Commission (US AEC) of Interim Acceptance Criteria (IAC) for the design of Emergency Core Cooling Systems (ECCS) in 1971 and consequent public rulemaking hearings in USA in 1972-73, 2) Three Mile Island (TMI-2) accident in 1979. The former brought to the design, construction and operation of experimental facilities (e.g. LOFT and Semiscale) initially aimed at addressing Large Break Loss Of Coolant Accident (LBLOCA) scenarios; the IAC also pushed the development of analytical work for numerical computer codes. The latter shifted the attention from LBLOCA to Small Break LOCA (SBLOCA). Specific experimental programs started (BETHSY, LOBI, etc., reported in Figure 1). Gathering of experimental Data Base (DB) for Accident Scenarios (AS) started.

The need to validate computer codes and the complexity of AS at the basis of the validation brought to the decision to identify and to characterize phenomenological windows and phenomena. The related processes of code validation and phenomena identification started by CSNI in the early 1980's, [3].

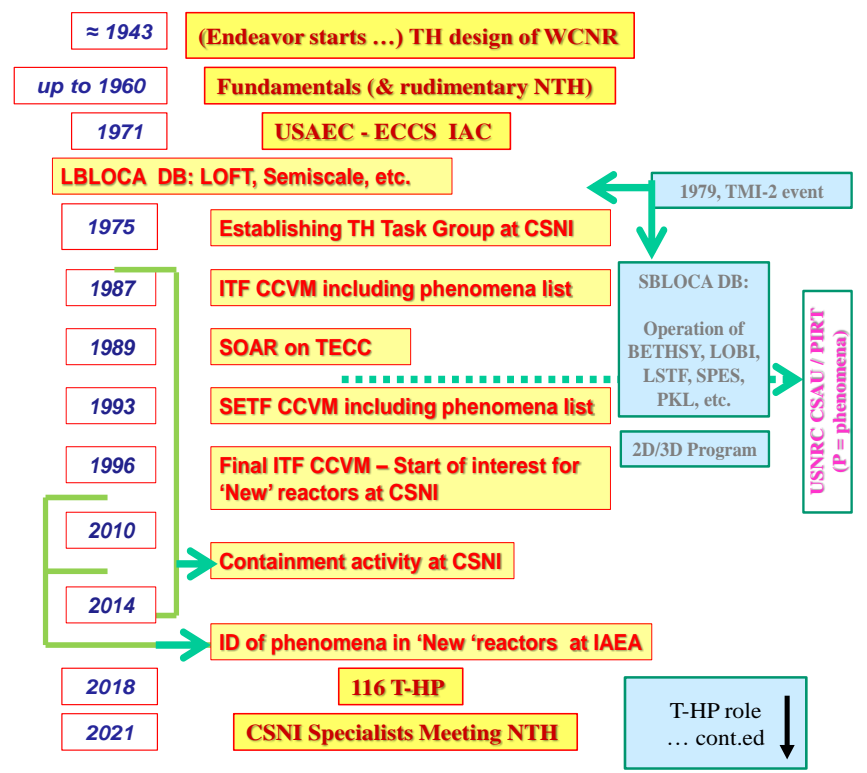

Figure 1. Outline of the history of T-HP, modified from [1]

The Integral Test Facilities (ITF: this acronym is used interchangeably with IET defined in the abstract), the Separate Effect Test Facilities (SETF, or SET), the Computer Code Validation Matrices (CCVM), the State of Art Report (SOAR) for Thermal hydraulics of ECCS (TECC) and, later on, the identification of Containment phenomena, constituted milestone products from CSNI activities. In 1989, US Nuclear Regulatory Commission (US NRC) introduced the Phenomena Identification and Ranking Table (PIRT) when proposing the Code Scaling Applicability and Uncertainty (CSAU), [6]. A parallel investigation within the International Atomic Energy Agency (IAEA) focused on 'advanced' (or 'new') reactor designs. The reader may find details on the topics above and the full reference to T-HP in [3]. A perspective for future use of T-HP might outcome from the CSNI Specialists Meeting scheduled by the end of 2021.

Two complementary visions for T-HP derive from Figure 2 and 3 (see e.g. [7]).

On the one hand, phenomena are prerequisite for developing the Partial Differential Equations (PDE) at the bases of system thermal hydraulics and Computational Fluid Dynamic (CFD) codes: this is specifically true in relation to the constitutive equations (embedded into the PDE) and to the needs for validation. The predicted WCNR performance depends upon T-HP modeling and knowledge, Figure 2.

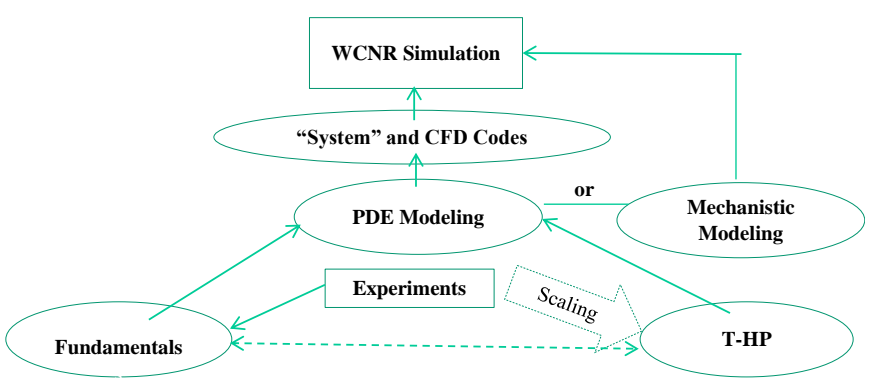

Figure 2. Role of T-HP in NTH

On the other hand, a (as far as possible) systematic analysis of a few hundred experiments in SETF and ITF, a variety of code calculation results and recorded data from nuclear reactor transient situations (e.g. including occurred accidents) brought to the identification and characterization of T-HP, Figure 3.

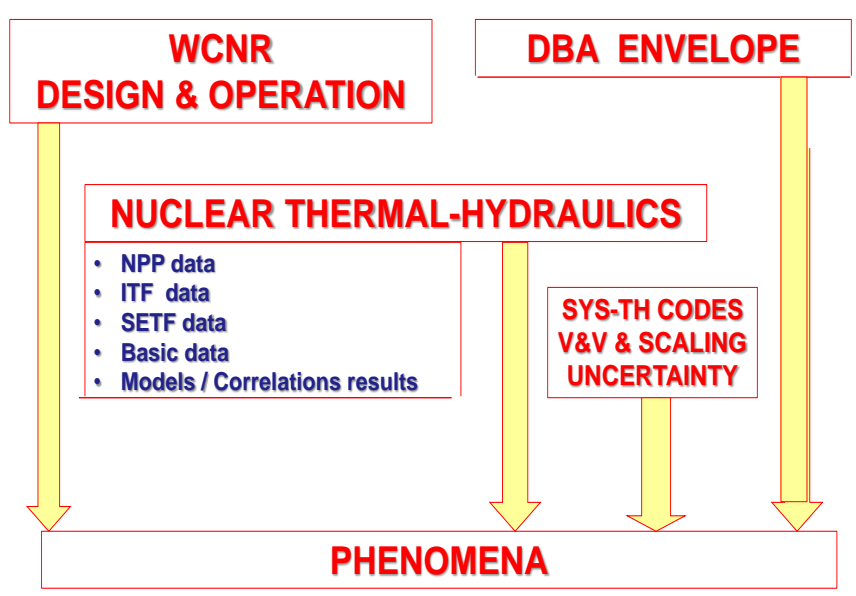

Figure 3. Derivation of T-HP, modified from [3]

The Design Basis Accident (DBA, also called by IAEA, Design Basis Conditions, DBC) framework is relevant for the identification and characterization of T-HP, as well as the processes for code development and scaling (see also Figure 2), Verification and Validation (V\&V) and uncertainty evaluation. 


\section{THE LIST OF 116 T-HP}

The experiments or scaled accident scenarios, performed in a couple dozen ITF and in a thousand SETF brought to the selection of two lists of qualified facilities. BWR, mostly those equipped with jet pumps, and PWR with either U-Tubes Steam Generators (UTSG) or Once Through Steam Generators (OTSG), were at the center of attention.

An evaluation followed for each experiment of the scaling rationale, the quality of instrumentation and the applicability (to BWR and PWR conditions) of parameter ranges. The impact of experimental data upon the development and the $\mathrm{V} \& \mathrm{~V}$ processes of codes paved the way for the selection of tests in the matrices, i.e. the CCVM. Deep reviews by scientists, managers and representatives of research, industry and regulatory body organizations, allowed the finalization of reports $[8,9]$.

Later on, different groups of scientists developed new and reduced scope CCVM by considering the following reactors, components and specific accident scenarios (the list of references in [3] cites individual related reports):

(a) PWR-type, Russian design reactors (VVER-440 and VVER-1000) equipped with Horizontal Steam Generators (HOSG).

(b) Reactors designs involving the use of natural circulation for cooling (noticeably AP-600 and SBWR) where a tight interaction between reactor coolant system and containment occurs following an accident.

(c) Canadian Deuterium (natural) Uranium (CANDU) reactors with horizontal-channel, core, also called Pressurized Heavy Water Reactor (PHWR).

(d) BWR-type, Russian design reactors (RBMK) and Atucha-type reactors, or PHWR with vertical-channels and reactor pressure vessel: expected T-HP added by the authors of [3].

(e) Water-cooled Small Modular Reactor (SMR) designs with heat exchangers into the reactor pressure vessel.

(f) Containment systems, distinguishing between full pressure (in PWR) and pressure suppression system (in BWR); in the last case, an early CSNI report included suitable information.

(g) Accident Management (AM) scenarios including the thermal hydraulic conditions and parameter ranges expected in 'Beyond' DBA (BDBA, recently characterized as Design Extension Conditions, region A, DEC-A by IAEA), before loss of core structural integrity.

Information from 'all' (as far as possible) international institutions reports, OECD/NEA and IAEA, dealing with thermal hydraulic phenomena was gathered; the list of $116 \mathrm{~T}$ HP in alphabetic order was issued, [3].

As taken from [3] and related to [1], “... 47 accident scenarios $(A S)$, calculated in relation to 13 water-cooled nuclear reactors (WCNR), discussed in 68 reference documents (RD), utilizing 15 generalized (thermal hydraulic) parameters (GP), have been ' $a$ posteriori' cross-linked with 116 phenomena (T-HP) in order to prove the origin of phenomena. The cross-link process also shows the direct connection between phenomena and nuclear reactor safety".

Table 1 deals with the list of 116 T-HP in alphabetic order (parts 1 and 2). Phenomena associated with a number in the first column form the list of selected T-HP. Additional information in [3], not part of the present table, allows further characterization for each phenomenon, e.g. which category a) to $\mathrm{g}$ ) is concerned, cross-connection of T-HP, etc. Phenomena without a corresponding number constitute typical alternative identification (sometimes synonymous) of T-HP part of the list. The last row of Table 1 (part 2) includes acronyms in the table.

The description of each T-HP ([1], Chapter 6), beyond the scope here, includes information about modeling capabilities and adequacy of experimental database. The use of selected THP for characterizing scaling capabilities of numerical codes and current state of knowledge in NTH can be found in documents cited in [3].

Table 1. The list of $116 \mathrm{~T}-\mathrm{HP}$, part 1

\begin{tabular}{|c|c|}
\hline No & T-HP Identification \\
\hline $\mathbf{1}$ & Accumulator behavior \\
\hline $\mathbf{2}$ & Asymmetric loop behavior \\
\hline $\mathbf{3}$ & Asymmetry due to the presence of a dam \\
\hline & Behavior of check valves \\
\hline $\mathbf{5}$ & Behavior of containment emergency systems (e.g. PCCS) \\
\hline $\mathbf{6}$ & Behavior of core make-up tanks \\
\hline $\mathbf{7}$ & Behavior of density locks \\
\hline $\mathbf{8}$ & Behavior of emergency heat exchangers including PRHR and IC \\
\hline $\mathbf{9}$ & Behavior of large pools of liquid \\
\hline $\mathbf{1 0}$ & Blow-down \\
\hline & Boiler condenser mode (of NC) \\
\hline $\mathbf{1 1}$ & Boil-off \\
\hline $\mathbf{1 2}$ & Coron mixing and transport \\
\hline $\mathbf{1 3}$ & CCF/CCFL-Down-comer \\
\hline $\mathbf{1 4}$ & CCF/CCFL-HL \& CL (including connection with RPV) \\
\hline $\mathbf{1 5}$ & CCF/CCFL-SG tubes \\
\hline $\mathbf{1 6}$ & CCF/CCFL-Surge-line \\
\hline $\mathbf{1 7}$ & CCF/CCFL-UTP \\
\hline & Centrifugal pump \\
\hline $\mathbf{1 8}$ & Condensation in stratified conditions-Horizontal Pipes \\
\hline $\mathbf{1 9}$ & Condensation in stratified conditions-PRZ \\
\hline $\mathbf{2 0}$ & \\
\hline $\mathbf{2 1}$ & Collapsed level behavior in down-comer \\
\hline $\mathbf{2 2}$ & Condensation due to heat removal \\
\hline $\mathbf{2 3}$ & Condensation due to pressurization \\
\hline & \\
\hline
\end{tabular}




\begin{tabular}{|c|c|}
\hline 24 & Condensation in stratified conditions-SG-PS \\
\hline 25 & Condensation in stratified conditions-SG-SS \& BWR-PSP \\
\hline \multirow[t]{2}{*}{26} & Containment emergency systems including passive cooling \\
\hline & Containment pressure and temperature \\
\hline 27 & Containment pump performance including sump clogging \\
\hline \multirow[t]{2}{*}{28} & Core thermal-hydraulics \\
\hline & Core wide void and flow distribution \\
\hline 29 & CRGT flashing \\
\hline \multirow[t]{5}{*}{30} & Critical and supercritical flow in discharge pipes \\
\hline & Critical flow \\
\hline & Critical Power Ratio \\
\hline & De-entrainment \\
\hline & Depressurization \\
\hline \multirow[t]{2}{*}{31} & ECC bypass/down-comer penetration \\
\hline & ECC mixing and condensation \\
\hline 32 & Entrainment/De-entrainment-Core \\
\hline 33 & Entrainment/De-entrainment-Down-comer \\
\hline 34 & Entrainment/De-entrainment-Hot leg with ECCI \\
\hline 35 & Entrainment/De-entrainment-SG mixing chamber \\
\hline 36 & Entrainment/De-entrainment-SG tubes \\
\hline 37 & Entrainment/De-entrainment-UP \\
\hline 38 & Evaporation due to depressurization (e.g. geom. discontinuities) \\
\hline 39 & Evaporation due to heat input \\
\hline 40 & Flow through openings \\
\hline 41 & Global multi-D fluid temperature, void and flow distribution-Core \\
\hline 42 & Global multi-D fluid temperature, void and flow distribution-DC \\
\hline 43 & Global multi-D fluid temperature, void and flow distribution-SG SS \\
\hline 44 & Global multi-D fluid temperature, void and flow distribution-UP \\
\hline 45 & Gravity driven reflood \\
\hline 46 & Horizontal heated channel HT \\
\hline 47 & HT [NCO, FCO, SNB, SANB, CHF, post-CHF]-Core, SG, structures \\
\hline 48 & HT [radiation]-core \\
\hline 49 & HT [condensation]-SG structures \\
\hline 50 & HT condensation in containment structures., w- w/o non-condensable \\
\hline \multirow[t]{2}{*}{51} & Impeller pump behavior \\
\hline & Instability (in boiling channels) \\
\hline 52 & Interfacial friction in horizontal flow \\
\hline 53 & Interfacial friction in vertical flow \\
\hline 54 & Intermittent 2-phase $\mathrm{NC}$ \\
\hline 55 & Internal pump behavior (specific geometry) \\
\hline 56 & Jet pump behavior \\
\hline \multirow[t]{2}{*}{57} & Liquid accumulation in horizontal SG tubes \\
\hline & Liquid carry-over \\
\hline 58 & Liquid temperature stratification \\
\hline 59 & Liquid-Vapor mixing with condensation-Core \\
\hline 60 & Liquid-Vapor mixing with condensation-Down-comer \\
\hline 61 & Liquid-Vapor mixing with condensation-ECCI in HL and CL \\
\hline 62 & Liquid-Vapor mixing with condensation-Lower plenum \\
\hline 63 & Liquid-Vapor mixing with condensation-SG mixing chamber \\
\hline 64 & Liquid-Vapor mixing with condensation-UP \\
\hline 65 & Loop seal filling and clearance (or clearing) \\
\hline 66 & LP entrainment \\
\hline \multirow[t]{2}{*}{67} & LP flashing \\
\hline & Mixture level \& entrainment-Core, down-comer and SG SS \\
\hline 68 & NC, 1-phase \& 2-phase-PS \& SS \\
\hline 69 & $\mathrm{NC}$ core and down-comer \\
\hline 70 & NC core bypass, hot and cold bundles \\
\hline 71 & NC core, gap, down-comer, dummy elements \\
\hline 72 & NC core, vent valves, down-comer \\
\hline 73 & NC with horizontal SG \\
\hline 74 & NC RPV and containment \& various system configurations \\
\hline 75 & Natural convection and $\mathrm{H} 2$ distribution \\
\hline \multirow[t]{2}{*}{76} & Non condensable gas effect including condensation HT in RCS \\
\hline & Nuclear fuel behavior \\
\hline \multirow[t]{2}{*}{77} & Nuclear thermal-hydraulics feedback and spatial effect \\
\hline & Nuclear thermal-hydraulics instabilities \\
\hline 78 & Parallel channel effects and instabilities PCEI \\
\hline 79 & Phase separation at branches (including effect on TPCF) \\
\hline
\end{tabular}




\begin{tabular}{|c|c|}
\hline 80 & Phase separation/vertical flow with and w/o mixture level-Core \\
\hline 81 & Phase separation/vertical flow with and w/o mixture level - DC \\
\hline 82 & Phase separation/vertical flow w- w/o mixture level-Pipes \& Plena \\
\hline 83 & Pool formation in UP \\
\hline 84 & Pressure drops at geometric discontinuities, including containment \\
\hline 85 & Pressure wave propagation including CIWH \\
\hline 86 & Pressure-temperature increase $\&$ boiling due to energy/mass input \\
\hline 87 & PRZ thermal-hydraulics \\
\hline 88 & QF propagation/rewet-Fuel rods \\
\hline 89 & QF propagation/rewet-Channel walls, Water rods \\
\hline 90 & Refill including loop refill in PWR-O \\
\hline 91 & Reflood \\
\hline \multirow[t]{2}{*}{92} & Reflux condenser mode and CCFL \\
\hline & Return to Nucleate Boiling (RNB) \\
\hline 93 & Separator behavior (flooding, steam penetration, liquid carry-over) \\
\hline 94 & SG siphon draining (SG interaction with ESF, including gravity driven) \\
\hline 95 & Spray effects-Containment \\
\hline 96 & Spray effects-Core (including cooling and distribution) \\
\hline 97 & Spray effects-OTSG SS \\
\hline 98 & Spray effects-PRZ \\
\hline 99 & Steam binding (liquid carry-over, etc.) \\
\hline 100 & Steam dryer behavior \\
\hline 101 & Steam line dynamics \\
\hline 102 & Stratification in horizontal flow-Pipes (in 1-phase \& 2-phase) \\
\hline 103 & Stratification of boron \\
\hline 104 & Structural heat and heat losses \\
\hline 105 & Surge-line hydraulics \\
\hline 106 & Superheating in OTSG SS \\
\hline 107 & Thermal-hydraulics - Nuclear fuel feedback \\
\hline 108 & Thermal-hydraulics of horizontal SG, PS and SS \\
\hline 109 & Thermal-hydraulics of OTSG, PS and SS \\
\hline 110 & TPCF-Breaks \\
\hline 111 & TPCF-Pipes \\
\hline 112 & TPCF-Valves \\
\hline \multirow[t]{4}{*}{113} & Tracking of non-condensable gases \\
\hline & Valve leak flow (construction, operation, maintenance) \\
\hline & Vapor (or steam) carry-under \\
\hline & Vapor pull through \\
\hline 114 & Ventilation blower characteristics \\
\hline 115 & Void collapse and temperature distribution during pressurization \\
\hline \multirow[t]{2}{*}{116} & Wall to fluid friction \\
\hline & Water accumulation in horizontal SG tubes \\
\hline \multicolumn{2}{|r|}{ 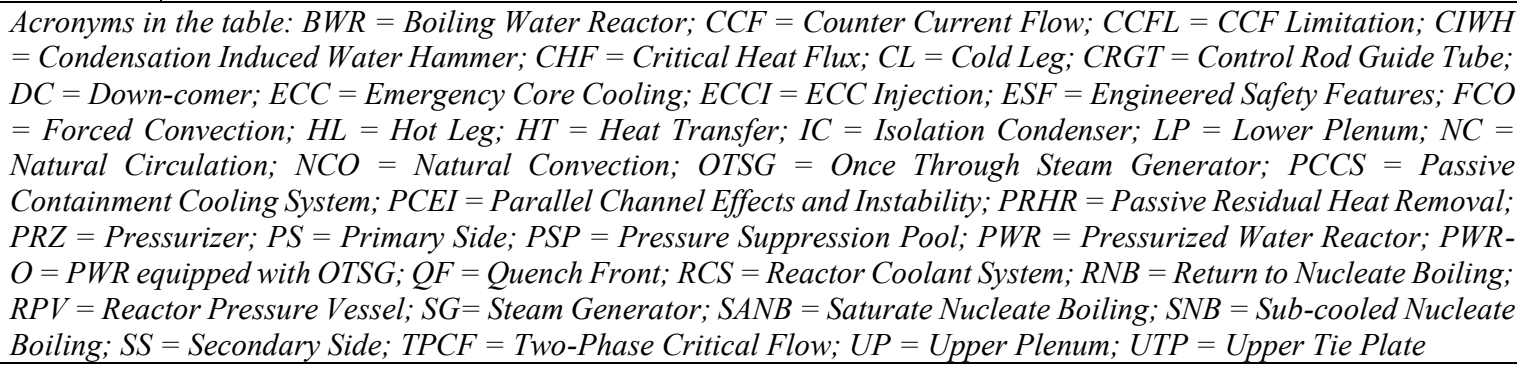 } \\
\hline
\end{tabular}

\section{PERSPECTIVE USE OF T-HP}

Although T-HP identified in [8, 9] already found applications e.g. in the areas of $\mathrm{V} \& \mathrm{~V}$ and scaling, the issue here is to prepare the basis for a systematic use of the $116 \mathrm{~T}$ HP list, see also [3].

The first (hidden) step, expected from a newly formed (possibly CSNI) group of experts, is to amend and finally accept the list, [3], and the descriptions in [1], Chapter 6. The notes below aim at supporting in this endeavor.

Figure 4 provides a summary view for the origins of T-HP, as of today the situation and the areas of NTH for possible applications. Table 2 gives a guidance related to the last item.

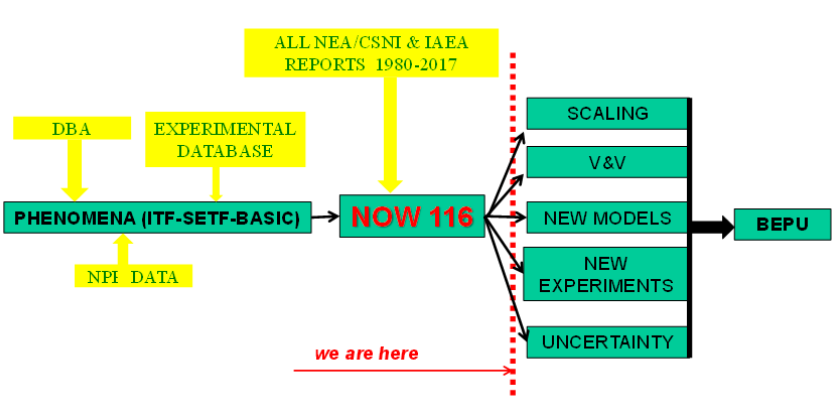

Figure 4. Perspective use of T-HP: Topics 
Let us stress again, Figure 4, that phenomena derive from experiments and code applications (DBA) and are the synthesis of $68 \mathrm{RD}$ issued by NEA/CSNI and IAEA. The NTH areas for applications are scaling, [10], $\mathrm{V} \& \mathrm{~V}$ [1], uncertainty
$[6,11,12]$, new experiments and models. The Best Estimate Plus Uncertainty (BEPU) framework, [13], includes all those areas. Furthermore, scaling, V\&V, uncertainty and BEPU constitute 'procedures in NTH', [4].

Table 2. Perspective use of T-HP, a systematic approach

\begin{tabular}{|c|c|c|c|c|c|c|c|c|}
\hline \multirow[b]{2}{*}{ No } & \multirow[b]{2}{*}{ T-HP } & \multirow{2}{*}{$\begin{array}{c}\text { CONSTITUTIVE } \\
\text { LAW / LAWS } \\
\text { (applicable) }\end{array}$} & \multirow{2}{*}{$\begin{array}{c}\text { SPECIAL } \\
\text { MODEL } \\
\text { need }\end{array}$} & \multicolumn{2}{|c|}{ SCALING } & \multirow{2}{*}{$\begin{array}{c}\text { UNCERTAINTY } \\
\text { PARAMETERS } \\
\text { relevant }\end{array}$} & \multirow{2}{*}{\begin{tabular}{|c} 
MECHANISTIC \\
IODELING cross- \\
link
\end{tabular}} & \multirow{2}{*}{$\begin{array}{c}\text { PRIORITY } \\
\text { (for new } \\
\text { research) }\end{array}$} \\
\hline & & & & $\begin{array}{c}\text { SET/IET } \\
\text { data }\end{array}$ & $\begin{array}{c}\text { Constitutive } \\
\text { laws }\end{array}$ & & & \\
\hline 1 & $\begin{array}{c}\text { Accumulator } \\
\text { behavior }\end{array}$ & & & & & & & \\
\hline$\ldots$ & $\ldots$ & & & & & & & \\
\hline$\ldots$ & $\ldots$ & & & & & & & \\
\hline & $\ldots$ & & & & & & & \\
\hline 116 & $\begin{array}{l}\text { Wall to fluid } \\
\text { friction }\end{array}$ & & & & & & & \\
\hline
\end{tabular}

The filling of Table 2, i.e. adding the $116 \mathrm{~T}-\mathrm{HP}$ in the $2^{\text {nd }}$ column, aims at a comprehensive and common understanding of current system thermal hydraulics, [4]: this would lead to the closure of a 40 -years long process.

Starting from the third column of the table (i.e. counting from left to right), the following activities are relevant in relation to each phenomenon and an assigned numerical code (when needed):

- The connection between phenomena and constitutive laws ( $3^{\text {rd }}$ column) or special models ( $4^{\text {th }}$ column) becomes straightforward. Here, we recall that the constitutive laws are part of PDE while special models are included in the numerical solution of codes (i.e. outside PDE) for the prediction of any AS.

- A suitable number of SETF (and ITF) data characterize the assigned phenomenon addressing the scaling issue ( $5^{\text {th }}$ column), [10]: data should be available for the same phenomenon at different scales from qualified databases.

- Validation against scaling of constitutive laws and special models is, eventually, an outcome from the sixth column: at least three data sets are necessary in a suitable application, as derived from differently scaled ITF (or SETF), [14]; qualitative and quantitative thresholds are available for the acceptability of code calculation results.

- Based on the comparison with experimental data, each phenomenon becomes both an origin for uncertainty and a way to quantify uncertainty: the identification and the characterization of physical parameters and related ranges of variations (PP\&R) constitute the result from the seventh column, see e.g. [15] and [16].

- Mechanistic modeling is an alternative way for reactor simulation (Fig. 2): “... regardless of the scale of phenomena under investigation ... a thorough and critical analysis of underlying physics is a key factor to improve our understanding ..." [17]. The objective for the eighth column is to establish a cross-link between T-HP and mechanistic modeling.

- Research priority is an outcome from filling the columns 3 to 8: selected prioritized T-HP may enter the process proposed in [18].

\section{KNOWLEDGE STATUS FOR SELECTED T-HP}

Understanding the current inadequacies in the application of models and numerical codes to the calculation of T-HP is essential for any decision step in previous section (i.e. filling the Table 2). However, a systematic overview of predictive capabilities for each phenomenon is beyond the scope (for this paper or for any other paper).

Hereafter, snapshot information related to four T-HP provide an idea of amount of errors in predictions and of challenges in modeling: we do not have the objective of summarizing the knowledge available from hundreds or thousands papers dealing with each concerned phenomenon.

\subsection{CCFL, T-HP 14 in Table 1}

CCFL may occur at any geometric discontinuity and even in horizontal pipes (typically, non-fully developed flow conditions) free of obstacles.

It is unavoidably a transient phenomenon, e.g. flooding conditions change with time and creation of a pool of liquid downstream flooding or CCFL occurrence. However, SETF experiments and model developments make use of the 'quasisteady' condition hypotheses.

Wallis and Kutateladze pioneered investigations in the area, early in the 1960's, bringing to the well-known formulations:

$$
\begin{aligned}
& j_{g}^{* 1 / 2}+m_{w a} j_{f}^{* 1 / 2}=C_{w a} \\
& K_{g}^{1 / 2}+m_{k u} K_{f}^{1 / 2}=C_{k u}
\end{aligned}
$$

where, the flooding parameters are, respectively,

$$
j_{k}^{*}=j_{k}\left[\frac{\rho_{k}}{g d\left(\rho_{f}-\rho_{g}\right)}\right]^{1 / 2}
$$

and

$$
K_{k}=j_{k}\left[\frac{\rho_{k}^{2}}{g \sigma\left(\rho_{f}-\rho_{g}\right)}\right]^{1 / 4}
$$

Later on, it was found, [19], that a force-momentum balance applied to a control volume in vertical flow-reversal conditions leads to eq. (1) if

$$
\tau_{i}=\frac{1}{2} c_{i}\left(\rho_{g}^{1 / 2} w_{g i}+\rho_{f}^{1 / 2} w_{f}\right)^{2}
$$

The complexity and the difficult predictability of the flooding phenomenon derive from Figure 5, [20] and [21], top and bottom diagram, respectively. 

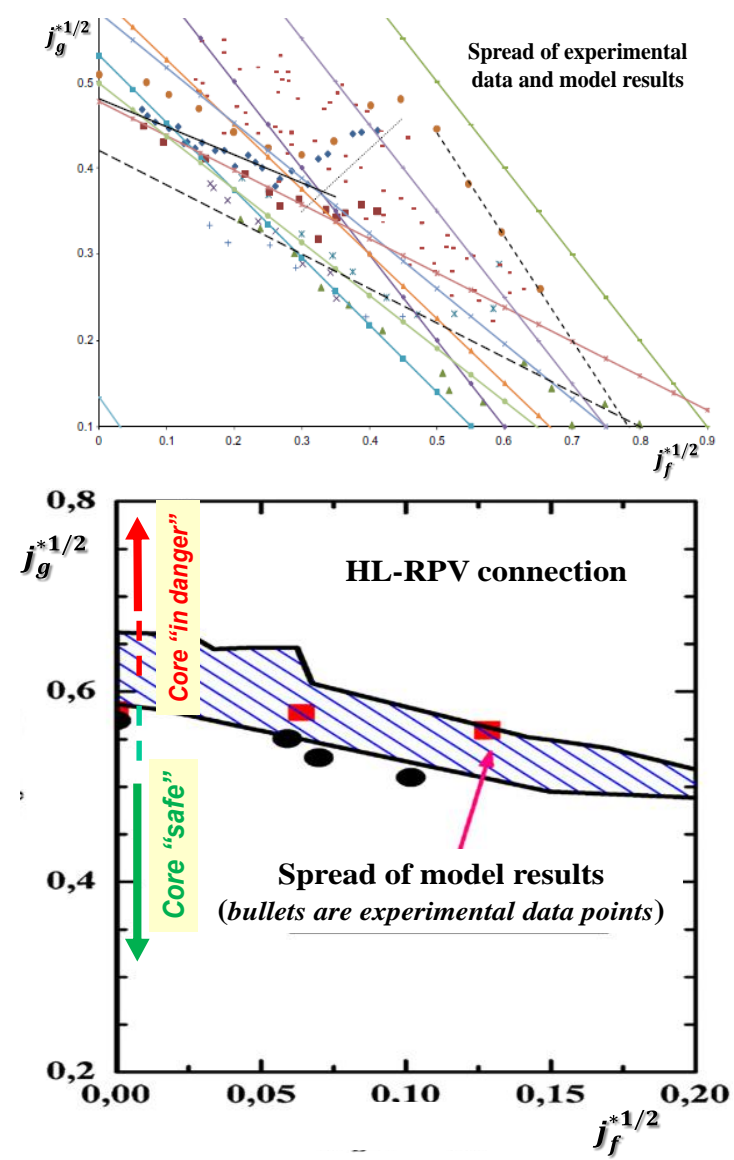

Figure 5. Flooding and CCFL $\left(j_{f}^{*}=0\right)$. Top: spread of experimental and calculated data in a vertical pipe, adapted from [20]. Bottom: HL-RPV geometry, adapted from [21]

From the right side of bottom diagram in Figure 5, one may derive the impact of CCFL prediction at the HL-RPV connection upon the safety analysis of the LBLOCA in Atucha-2 reactor, [22]. If calculated $j_{g}^{*}$ remains below 0.60 , reflood occurs timely (i.e. no safety concern) following ECC injection; otherwise, if calculated $j_{g}^{*}>0.75$, rod surface temperature in the core may overpass safety limits. The spread associated with the knowledge of CCFL (dotted lines in the diagram) imposed a specific uncertainty investigation to prove suitable core cooling conditions.

\subsection{CHF, T-HP 47 in Table 1}

CHF is at the center of attention of NTH scientists because of the need to ensure core operation in nucleate boiling heat transfer regime and, at the same time, to allow the maximum value for linear power during operation of WCNR.

We note the publication of hundreds correlations and the availability of data from thousands experiments, see e.g. [23]: errors derived from the application of any correlation in predicting an enough large number of CHF experimental datapoints are barely below $20 \%$, on average.

Therefore, Kirillov and Groeneveld (and co-workers) during a life-long engagement, almost simultaneously, launched an empirical approach so-called Look-Up Tables (LUT). Measured CHF data-points fill thousands virtual cubes in a three-dimensional space, where independent variables are local quality, mass flow and pressure (further details in [23]). Nowadays, almost all thermal hydraulic system codes adopt the LUT approach for predicting CHF for WCNR safety analyses.

System thermal hydraulic code-developers who are members of the FONESYS, [24], decided to compare CHF code predictions referring to an assigned fuel assembly. Different codes simulated an imposed flow-decrease transient starting from nominal operation. Figure 6 shows key results.

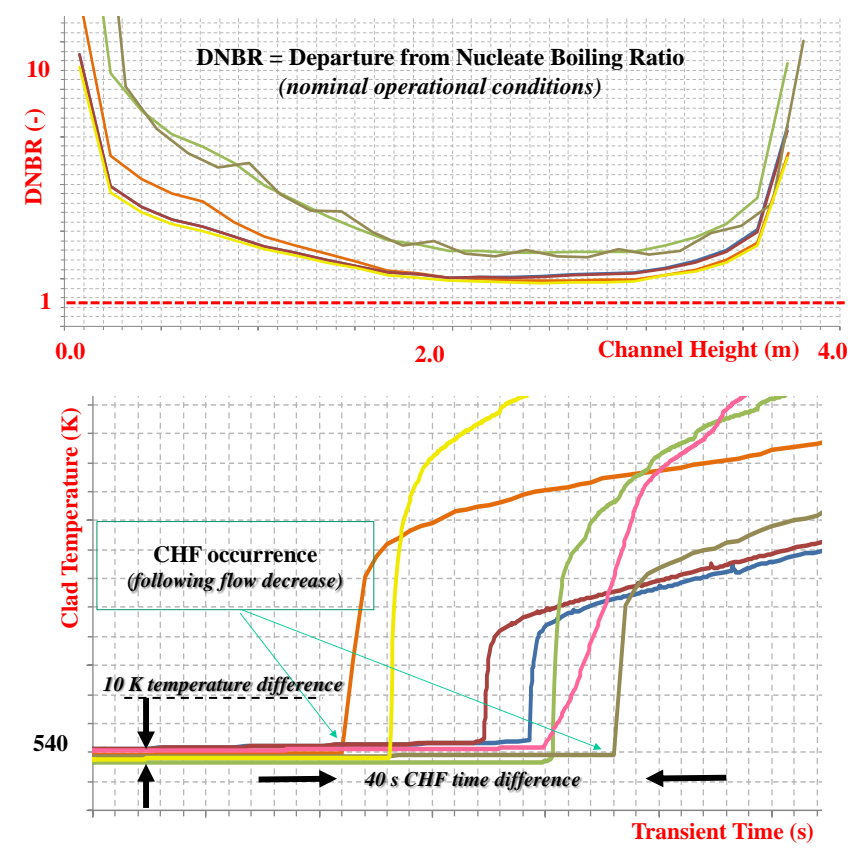

Figure 6. CHF calculations by different codes of a virtual core channel. Top: DNBR along channel axis at nominal conditions. Bottom: CHF occurrence following a decreaseof-flow transient

We can summarize the outcomes related either to initial steady state (top) or to the flow-decrease transient (bottom):

(a) As expected, the entire channel is in nucleate boiling conditions; however, the minimum value of the DNBR is not the same for all calculations (i.e. in the range 1.4 to 2.0, approximately).

(b) DNBR values have larger differences in the bottom one meter of the channel.

(c) Initial clad temperatures differ for about $10 \mathrm{~K}$ at the beginning of the transient (bottom diagram); a portion of this difference depends upon the concerned axial location, i.e. the place where CHF occurs first.

(d) Times of CHF occurrence differ for about 40 seconds in a transient where the 'latest' calculation predicts dry-out at about $80 \mathrm{~s}$.

(e) Difference in rod surface temperature after the CHF occurrence is due also to post-CHF model.

\subsection{Reflood, T-HP 91 in Table 1}

The modern history of reflood modeling started in 1968 with the (well-known) Yamanouchi milestone-paper. He derived a two-dimensional equation for conduction heat transfer in the clad:

$$
\frac{\partial^{2} T}{\partial y^{2}}+\frac{\partial^{2} T}{\partial z^{2}}=\rho_{c l} c_{p}^{c l} \kappa_{c l} U \frac{\partial T}{\partial z}
$$


The Yamanouchi idea consists in establishing the link between the Quench Front (QF) velocity (U) and the time derivative in the conduction equation (i.e., $\frac{\partial T}{\partial t}=U \frac{\partial T}{\partial z}$ ) solved within a domain of the clad downstream the QF. The introduction of subsequent assumptions brought to the relationship:

$$
\check{\mathrm{h}}_{r e}=\left(\rho_{c l} c_{p}^{c l} U\right)^{2} \frac{\delta}{2 \kappa}\left\{\left[\frac{2\left(T_{w-s}-T_{M F B}\right)}{T_{M F B}-T_{s a t}}+1\right]-1\right\}
$$

Current codes for nuclear reactor safety analyses make use of the structure of the above formula. This is at the origin of large discrepancies among predictions: following the BEMUSE project, [12], reflood is at the center of attention for derivation of uncertain parameters and ranges $[15,16]$.

Figure 7 deals with two complex reflood aspects: the 'sametime' or the homogeneous reflood and the multiple (apparently random) values of $T_{M F B}$.
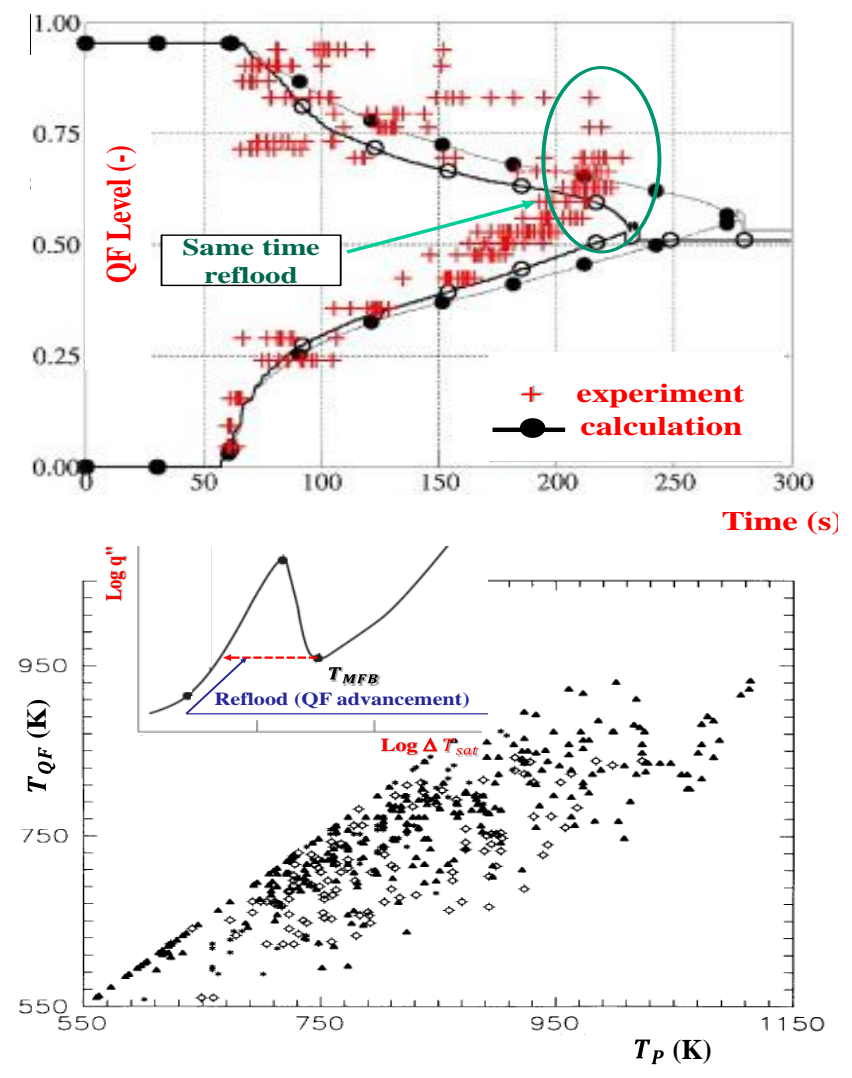

Figure 7. Reflood. Top: QF advancement vs time, 'sametime' reflood. Bottom: $\left(\mathrm{T}_{\mathrm{QF}} \approx\right) \mathrm{T}_{\mathrm{MFB}}$ vs $\mathrm{T}_{\mathrm{P}}$, several $\mathrm{T}_{\mathrm{MFB}}$ values for the same $T_{P}$, modified from [26]

Predicted 'uniform' advancements of QF from bottom-totop and from top-to-bottom of channel (full lines) leads to gathering of two fronts at about middle of channel height at around $250 \mathrm{~s}$, while experimental data ('+' points) exhibit a 'same-time reflood' at around $220 \mathrm{~s}$, top diagram. Similar experimental and corresponding calculated data are reported in [25] for high velocity reflood. 'Same-time' reflood, or homogeneous reflood, is inconsistent with the derivation of eq. (7): a different modeling approach is necessary.

The bottom diagram shows not widely disseminated reflood data for nuclear fuel, measured in Halden nuclear reactor, [26]. Two issues are concerned, widely debated in scientific literature: (a) The equivalence between $\mathrm{T}_{\mathrm{QF}}$, or the temperature when a steep change occurs in the time trend clad-temperature vs time, and $\mathrm{T}_{\mathrm{MFB}}$.

(b) The widely spread values for $\mathrm{T}_{\mathrm{QF}}$, whatever is the value of the maximum temperature experienced at the same location during the early period of the transient.

\subsection{TPCF, T-HP 111 in Table 1}

When Adm. Rickover took the decision to use water as coolant-moderator of nuclear reactors, Two-Phase Critical Flow (TPCF) became of technological interest. Papers summarizing related investigations appeared early in the 1950's.

Moody and Fauske are the pioneers who published reference TPCF models in the early 1960's. In order to introduce to the complexity of the issue, we introduce a seedinformation of the Moody model. Moody considered the perfect gas theory and proposed the following energy balance in a control volume including the region from a high-pressure reservoir and a hypothetic break connecting with the lowpressure environment:

$$
\begin{gathered}
h_{0}\left(x_{0}, p_{0}\right)=x\left[h_{g}(p)+\frac{w_{g}^{2}}{2}\right] \\
+(1-x)\left[h_{f}(p)+\frac{w_{f}^{2}}{2}\right]
\end{gathered}
$$

Moody obtained one equation in four unknowns: $\mathrm{w}_{\mathrm{g}}, \mathrm{w}_{\mathrm{f}}, \mathrm{x}$ and $p$, all at the break location. Following a change of variables, (he introduced two-phase mass flux, $\Gamma$, void fraction, $\alpha$, and slip ratio, $\mathrm{S}=\mathrm{wg}_{\mathrm{g}} / \mathrm{w}_{\mathrm{f}}$, so the unknowns become $\mathrm{S}, \alpha, \mathrm{p}, \Gamma$ ), he proposed three additional equations:

$$
\begin{gathered}
s_{0}=\text { const. (9), } \quad\left[\frac{\partial \Gamma}{\partial S}\right]_{p}=0 \quad(10), \quad\left[\frac{\partial \Gamma}{\partial p}\right]_{S} \\
=0
\end{gathered}
$$

The Eq. (9) 'neglects' friction and wall heat transfer in a highly changing velocities and temperature condition; Eq. (11) 'recalls' the perfect gas theory for critical flow; Eq. (10) is a mathematical condition (not having any connection with physics). Other hidden or evident approximations (incomplete list) are:

- No consideration of momentum balance, e.g. pressure drop due to acceleration, interfacial drag, etc.

- Velocity in reservoir assumed negligible.

- Quality in reservoir not affected by TPCF and related depressurization.

- Use of state equations in non-equilibrium conditions.

However, Moody model produced results that compete (nowadays) with hundreds recent models, in terms of accuracy of predictions for newly available experimental data. Notwithstanding efforts made by hundreds of scientists who published papers and correlations, errors in the comparison between measured and predicted values of TPCF are large and strongly depending upon $x_{0}$ : the largest value, of the order of $30 \%$ of measured values (also affected by uncertainties), occurs when $x_{0} \approx 0$.

Here we limit ourselves to report, Figure 8, the spread of data resulting from TPCF predictions to show the slow progress made in the area during 45 years. The upper and low diagrams report data from 1976, [27], already elaborated in 1980, [28], and 2020, [29], respectively. Both vertical axes 
report non-dimensional TPCF within the same range of values. However, horizontal axes are different: we use $x_{0}$ and transient time in top and bottom diagrams with $x_{0} \approx 0$. at $t=0$, for the data in the bottom diagrams.

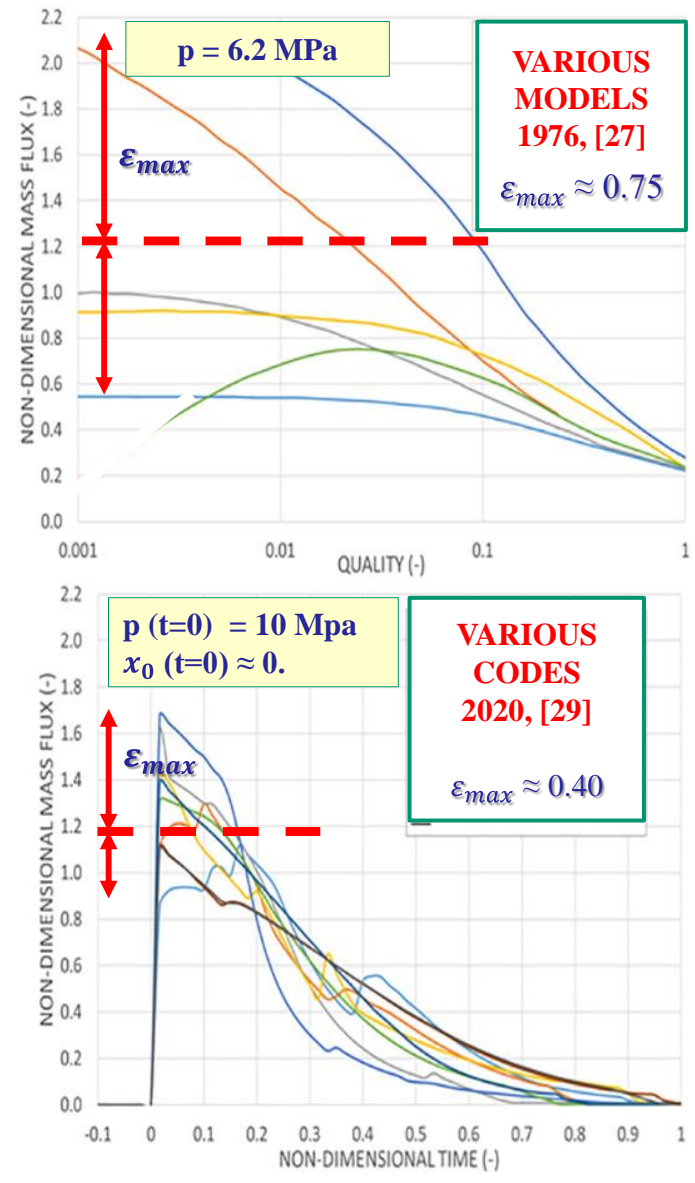

Figure 8. TPCF. Top: spread of models results in 1976, adapted from [27]. Bottom: spread of code results in 2020, adapted from [29]

\section{CONCLUSIONS}

A long-lasting and wide-range investigation performed by hundreds of scientists brought to the identification and characterization of 116 T-HP within nuclear thermal hydraulics technology. Snapshot notes dealing with CCFL, $\mathrm{CHF}$, reflood and TPCF (four of T-HP) confirm the complexity of the phenomena and the inaccuracies and the challenges in modeling.

The formulation of constitutive laws and the special models that are part of a numerical code should correspond with each individual phenomenon. However, this is not an objective pursued when developing a numerical code.

Procedures like accuracy quantification, $V \& V$, scaling and uncertainty take benefit from the identification and characterization of the 116 T-HP. For instance, experimental databases have been associated with selected phenomena with the aim to demonstrate their suitability for code validation.

The 'perspective T-HP table' (Table 2 in the text) involving experimental database, scaling, uncertainty, constitutive laws, mechanistic modeling and prioritization of research is the main outcome from the present investigation: the final step of a multi decade international research and the initial step for progressing in the area.

\section{ACKNOWLEDGMENT}

The authors thank many researchers who contributed to identify and characterize the list of T-HP: only a few of them are co-authors in reported references.

\section{REFERENCES}

[1] D'Auria, F. (2017). Thermal-hydraulics of water cooled nuclear reactors. Woodhead Publishing.

[2] Aksan, S.R., Bessette, D., Brittain, I., D'Auria, F.S., Gruber, P., Holmstrom, H.L.O., Zuber, N. (1987). CSNI code validation matrix of thermo-hydraulic codes for LWR LOCA and transients. CSNI, 132, Paris, France.

[3] Aksan, N., D'Auria, F., Glaeser, H. (2018). Thermalhydraulic phenomena for water cooled nuclear reactors. Nuclear Engineering and Design, 330: 166-186. https://doi.org/10.1016/j.nucengdes.2018.01.035

[4] D'Auria, F., Aksan, N., Hassan, Y. (2021). What is nuclear thermal hydraulics? OECD/NEA/CSNI Specialists Meeting on Transient Thermal-hydraulics in Water-Cooled Nuclear Reactors (SM-TH), P8, Dec. 1417, Madrid (Spain).

[5] D’Auria, F. (2019). Nuclear fission: from E. Fermi to Adm. Rickover, to industrial exploitation, to nowadays challenges. Advancement in Scientific and Engineering Research, 4(1):

17-30. https://doi.org/10.33495/aser_v4i1.19.102

[6] USNRC. (1989). Quantifying Reactor Safety Margins: Application of CSAU to a LBLOCA. NUREG/CR-5249, Washington, DC (USA).

[7] D'Auria, F., Aksan, N., Glaeser, H. (2021). Thermal hydraulic phenomena list. OECD/NEA/CSNI Specialists Meeting on Transient Thermal-hydraulics in WaterCooled Nuclear Reactors (SM-TH), P15, Dec. 14-17, Madrid (Spain).

[8] OECD/NEA/CSNI. (1994). [Authors: N. Aksan (Chairman), F. D’Auria, H. Glaeser, J. Lillington, R. Pochard, A. Sjöberg], Separate effects test matrix for thermal-hydraulic code validation. Volume I: Phenomena Characterization and Selection of Facilities and Tests, Volume II: Facility and Experiment Characteristics. NEA/CSNI/R(94)14/Part 1 and Part 2, OECD/NEA, Paris (F).

[9] OECD/NEA/CSNI. (1996). [Authors: A. Annunziato, H. Glaeser (Chairman), J.N. Lillington, P. Marsili, C. Renault, A. Sjöberg], CSNI Integral Test Facility Validation Matrix for the Assessment of ThermalHydraulic Codes for LWR LOCA and Transients; (rev. 1 of the original document issued in 1987), NEA/CSNI/ $\mathrm{R}(96) 17$, OECD, Paris (F).

[10] OECD/NEA/CSNI. (2017). [(Lead Authors) Bestion D., D’Auria F. (Ed.), Lien P., Nakamura H., (Contributors) Austregesilo H., Skorek T., Bae B.U., Choi K.Y., Kim K.D., Moon S. K., Martinez-Quiroga V., Reventos F. Mascari F., Schollenberger S., Umminger K., Reyes J.N., Rohatgi U.S. Wang W., Zaki T.]. Scaling in system thermal-Hydraulics applications to Nuclear Reactor safety and design: A State-of-the-Art-Report. NEA/CSNI/R(2016)14, JT034 11050, Paris (F).

[11] OECD/NEA/CSNI. (1998). [Authors: Wickett, T. (Ed.), D’Auria, F., Glaeser, H., Chojnacki, E., Lage, C. (Lead 
Authors), Sweet, D., Neil, A., Galassi, G.M., Belsito, S., Ingegneri, M., Gatta, P., Skorek, T., Hofer, E., Kloos, M., Ounsy, M., Sanchez, J.I.]. Report of the Uncertainty Methods Study for advanced best estimate thermalhydraulic code applications. Vols. I, II. NEA/CSNI/ $\mathrm{R}(97) 35$, Paris (F).

[12] Reventos, F., Glaeser, H., D’Auria, F., De Crécy, A. (2011). Uncertainty and sensitivity analysis for a nuclear power plant large break loss of coolant accident (LBLOCA) in the context of OECD BEMUSE programme. Int. Topical Meet. On Nuclear Reactor ThermalHydraulics (NURETH-14), Article No 355, Toronto (Ontario, Canada), Sept. 25-30.

[13] D'Auria, F. (2019). Best estimate plus uncertainty (BEPU): Status and perspective. Nuclear Engineering and Design, 352 : 110190. https://doi.org/10.1016/j.nucengdes.2019.110190

[14] D'auria, F., Debrecin, N., Galassi, G. M. (1995). Outline of the uncertainty methodology based on accuracy extrapolation. Nuclear Technology, 109(1): 21-38. https://doi.org/10.13182/NT109-21

[15] Skorek, T., de Crécy, A., Kovtonyuk, A., Petruzzi, A., Mendizábald, R., de Alfonso, E., Reventós, F., Freixa, J., Sarrette, C., Kyncl, M., Pernica, R., Baccou, J., Fouet, F., Probst, P., Chung, B.D., Tram, T.T., Oh, D.Y., Gusev, A., Falkov, A., Shvestovk, Y., Li, D., Liu, X., Zhang, J., Alku, T., Kurki, J., Jäger, W., Sánchez, V., Wicaksono, D., Zerkak, O., Pautz, A. (2019). Quantification of the uncertainty of the physical models in the system thermalhydraulic codes - PREMIUM benchmark. In Special Issue Trends and Perspectives in Nuclear Thermalhydraulics - to the memory of B. R. Sehgal, G. Yadigaroglu and G. F. Hewitt, [F. D'Auria Ed.], J. Nuclear Engineering and Design, 354, paper 110199, pp 1-23.

[16] Baccou, J., Zhang, J., Fillion, P., Damblin, G., Petruzzi, A., Mendizábal, R., Reventós, F., Skorek, T., Couplet, M., Iooss, B., Oh, D.Y., Takeda, T. (2019). Development of good practice guidance for quantification of thermalhydraulic code model input uncertainty. In Special Issue Trends and Perspectives in Nuclear Thermal-hydraulics - to the memory of B. R. Sehgal, G. Yadigaroglu and G. F. Hewitt, [F. D'Auria Ed.], J. Nuclear Engineering and Design, 354, paper 110173, pp. 1-13.

[17] Podowski, M.Z. (2019). Understanding two-phase flow and boiling heat transfer: challenges and paradoxes. In Special Issue Trends and Perspectives in Nuclear Thermal-hydraulics - to the memory of B. R. Sehgal, G. Yadigaroglu and G. F. Hewitt, [F. D'Auria Ed.], J. Nuclear Engineering and Design, 354, paper 110185, pp $1-10$.

[18] D'Auria, F. (2018). Prioritization of nuclear thermalhydraulics researches. Nuclear Engineering and Design, 340: $105-111$ https://doi.org/10.1016/j.nucengdes.2018.09.040

[19] Glaeser, H. (1992). Downcomer and tie plate countercurrent flow in the Upper Plenum Test Facility (UPTF). Nuclear Engineering and Design, 133(2): 259283. https://doi.org/10.1016/0029-5493(92)90186-Y

[20] Al Issa, S., Macian, R. (2011). A review of CCFL phenomenon. Annals of Nuclear Energy, 38(9): 17951819. https://doi.org/10.1016/j.anucene.2011.04.021

[21] Glaeser, H., Rohatgi, U.S. (2019). Scaling ability of the counter-current flow limitation (CCFL) correlations for

application to reactor thermal hydraulics. In Special Issue Trends and Perspectives in Nuclear Thermal-hydraulics - to the memory of B. R. Sehgal, G. Yadigaroglu and G. F. Hewitt, [F. D'Auria Ed.], J. Nuclear Engineering and Design, 354, paper 110226, pp 1-11.

[22] Mazzantini, O., Galassi, G.M., D'Auria, F. (2019). The role of nuclear thermal-hydraulics in the licensing of Atucha-II: The LBLOCA. In Special Issue Trends and Perspectives in Nuclear Thermal-hydraulics - to the memory of B. R. Sehgal, G. Yadigaroglu and G. F. Hewitt, [F. D'Auria Ed.], J. Nuclear Engineering and Design, 354, paper 110292, pp. 1-27.

[23] IAEA. (2001). [Lead Authors: Aksan N.(Chairman), D'Auria F., Groeneveld D., Kirillov P., Saha D., Badulescu A., Cleveland J.], Thermo-hydraulic Relationships for Advanced Water Cooled Reactors, TECDOC 1203, Vienna (A).

[24] Ahn, S.H., Aksan, N., Austregesilo, H., Bestion, D., Chung, B.D., D'Auria, F., Petruzzi, A. (2015). FONESYS: The forum \& network of system thermalhydraulic codes in nuclear reactor thermal-hydraulics. Nuclear Engineering and Design, 281: 103-113. https://doi.org/10.1016/j.nucengdes.2014.12.001

[25] Jin, Y., Cheung, F.B., Shirvan, K., Bajorek, S.M., Tien, K., Hoxie, C.L. (2020). Numerical investigation of rod bundle thermal-hydraulic behavior during reflood transients using COBRA-TF. Annals of Nuclear Energy, 148:

107708 .

https://doi.org/10.1016/j.anucene.2020.107708

[26] Svanholm, K., Breghi, M. P., D'Auria, F., Ianiri, R. (1995). Halden reactors IFA-511.2 and IFA-54x: Experimental series under adverse core cooling conditions. Experimental Thermal and Fluid Science, 11(1): $\quad 77-100 . \quad$ https://doi.org/10.1016/08941777(94)00138-X

[27] Ardron, K.H., Furness, R.A. (1976). A study of the critical flow models used in reactor blowdown analysis. Nuclear Engineering and Design, 39(2-3): 257-266. https://doi.org/10.1016/0029-5493(76)90074-1

[28] D'Auria, F., Vigni, P. (1980), Two-Phase Critical Flow Models. CSNI Report No 49, Paris, France.

[29] Lanfredini, M., Bestion, D., D'Auria, F., Aksan, N., Fillion, P., Gaillard, P., Wang, D. (2020). Critical flow prediction by system codes-Recent analyses made within the FONESYS network. Nuclear Engineering and Design, 366: 110731. https://doi.org/10.1016/j.nucengdes.2020.110731

\section{NOMENCLATURE}

c

C

$\mathrm{c}_{\mathrm{p}}$

d

g

$\mathrm{h}$

$\check{\mathrm{h}}$

j

m

$\mathrm{p}$

q"

S friction factor

constant based on system parameters (-)

specific heat, $\mathrm{J}^{\mathrm{kg}}{ }^{-1} \cdot \mathrm{K}^{-1}$

geometric dimension, $\mathrm{m}$

gravitational acceleration, $\mathrm{m} . \mathrm{s}^{-2}$

enthalpy, J. kg-1

heat transfer coefficient, W. $\mathrm{m}^{-2} \cdot \mathrm{K}^{-1}$

superficial velocity, $\mathrm{m} \cdot \mathrm{s}^{-1}$

multiplier for CCFL parameter (-)

pressure, N.m ${ }^{-2}$

heat flux, w. $\mathrm{m}^{-2}$

entropy, $\mathrm{J}^{\mathrm{kg}^{-1}} \cdot \mathrm{K}^{-1}$

slip ratio, dimensionless 
time, $\mathrm{s}$

temperature, $\mathrm{K}$

quench front velocity, $\mathrm{m} . \mathrm{s}^{-1}$

fluid velocity, $\mathrm{m} . \mathrm{s}^{-1}$

quality, dimensionless

geometry coordinate

geometry coordinate

$\begin{array}{ll}\mathrm{f} & \text { (saturated) liquid } \\ \mathrm{g} & \text { (saturated) vapor } \\ \mathrm{i} & \text { interface } \\ \mathrm{k} & \text { f or g } \\ \mathrm{ku} & \text { Kutateladze } \\ \mathrm{max} & \text { maximum } \\ \mathrm{MFB} & \text { minimum film boiling } \\ \mathrm{P} & \text { peak (maximum during a transient) } \\ \mathrm{QF} & \text { quench front } \approx \text { MFB } \\ \mathrm{re} & \text { Reflood } \\ \mathrm{sat} & \text { Saturation } \\ \text { wa } & \text { Wallis } \\ \text { W-s } & \text { wall-steam region } \\ 0 & \text { upstream reservoir condition }\end{array}$

\section{Superscripts}

surface tension N.m ${ }^{-1}$

shear stress N.m ${ }^{-2}$

$\begin{array}{ll}\mathrm{cl} & \text { clad material } \\ * & \text { non-dimensional }\end{array}$

\section{Subscripts}

$\mathrm{cl}$

clad material 